\title{
Considerations on the Post Education Course Examine Mechanism Innovation
}

\author{
Xin Wang ${ }^{\mathrm{a}}$, Xue Wang ${ }^{{ }^{\mathrm{b}}}$ and Xianggang Meng ${ }^{\mathrm{c}}$ \\ Armor Technique Institutes of china, Changchun 130117, China. \\ a37884960@qq.com, *Corresponding author Email: bkty098@126.com, 'cmtn556@126.com
}

Keywords: Professional education, Course assessment, Reform, Thinking.

\begin{abstract}
Course assessment is an important part of professional education, concerning the overall situation of professional education. As for the deepening of education reform, the traditional curriculum evaluation has been unable to meet the needs of professional education, reflects the strong hysteresis and not matching, this paper from the professional education course examination paper, analysis of the current problems existing in the curriculum evaluation, and puts forward some thought on the examination reform of education for the problem.
\end{abstract}

\section{Introduction}

Course assessment is widely and frequently in professional education teaching activities, is an important link in the teaching process, has the guiding and encouraging [1]. To grasp the profound national assessment policy at the same time, to maximize to test and promote science, to test and promote teaching, to test and promote the tube, the professional education courses, improving curriculum assessment.

\section{Current Professional Education Courses Features}

Curriculum assessment of student knowledge, intelligence, ability, personality and moral determination, is based on the talent cultivation objectives and programs, selected content and problem, process measurement and evaluation of their knowledge, skills in a certain way [2]. Therefore, the ability of reasonable evaluation method and evaluation methods for students to learn and use knowledge will produce far-reaching effect [3].

All aspects of the assessment of the curriculum reform involve the teaching objective, the talent training scheme, curriculum, teaching content, teaching methods, teaching evaluation. The characteristics of current professional education course examination:

2.1 Theoretical examination, practice examination as a supplement, content is more dependent on the teacher the teaching knowledge and teaching materials.

Course assessment to teaching, teachers teaching, textbook knowledge as the center, using written shut out of the way, students mainly through memory related knowledge to complete the examination, the examination students can systematically grasp the theory content, the methodical, systematic, complete, training students analyze problems in order to achieve and problem solving ability.

2.2 In strict accordance with the teaching goal as the assessment criteria, on the basis of personnel cultivation project assessment, to the exercise of good effects on students' comprehensive quality ability.

Curriculum evaluation is an important index to check out whether students to achieve the teaching objective, teaching objectives is mainly embodied through the course examination, at the present stage of professional education to the teaching goal as the inspection standard, at the same 
time in the development of the examination method reference personnel training plan, have a great role in promoting for the master degree of testing students knowledge and ability, but also can pass the examination to find out the teaching objectives and personnel training system in existence, in order to further revise and improve.

2.3 The curriculum assessment process is mature and stable, the formation of a standardized evaluation system.

Professional education course examination after long time running, the program has been mature and stable, standardized system corresponding to complete, the proposition, the system volume, invigilation, marking, assessment work link system specification, therefore, assessment work can follow the prescribed order, according to each link related management systems and procedures, can complete the assessment task.

\section{The Existence of the Problem of Education Course Examination}

Through the exploration and development of professional education, has made great progress, but in the course of examination gradually exposed some problems, these problems have hindered the development of vocational education, problems are mainly embodied in the following aspects:

\subsection{Assessment form is relatively single.}

Most of the courses in a final exam scores as their final grades. In class learning and students appear deviation, students for the exam and simple back questions, not to use the energy to master basic knowledge and basic skills, to learn, to learn before I can't without using, phenomenology. And evaluation is a one-time end of exams, students after the exam, the teacher and the students to have the opportunity of feedback and communication, the lack of corresponding feedback mechanism.

\subsection{The assessment content is not comprehensive enough.}

Curriculum assessment content mostly confined to textbooks, heavy theory light application, often with a test to decide the winner, application ability, analysis and problem solving ability can not comprehensively students. The resulting problems: one is not conducive to mobilize and bring into play the enthusiasm of teachers to explore the appraisal research, two is not conducive to a comprehensive assessment for students theoretical knowledge and practical skills, which are not well test the learning effect of students.

\subsection{The evaluation result is more important than process.}

The universities are mostly concerned about the evaluation results, by examination results to evaluate students are qualified, issue the relevant skills certificate, while ignoring the process to train students' innovative spirit, innovative ability. This will give students caused great psychological pressure and psychological, not conducive to the students' creativity and initiative, has seriously hindered the creative thinking training and development.

\section{Some Evaluation Reform Education Curriculum for Thinking}

For $\mathrm{Mr} \mathrm{Xi}$ "can fight, win" requirements, speed up the cultivation of high-quality talents, colleges and universities in the reform in education and teaching at the same time, must carry out the reform of evaluation necessary. For several aspects of examination education course reform needs to be considered:

\subsection{The post education curriculum evaluation should focus on solid theoretical, training} ability, reform to expand quality.

First of all to the appraisal theory knowledge, highlight the heavy difficulty. Is the necessary 
knowledge, to lay a good foundation for practical skills training, but also to avoid in order to achieve the best rate of so-called and evade the crucial point of the assessment content, realize this will and the personnel training goal less adapted; secondly, the application ability examination, without exception, require students to have spirit, innovation the innovation ability of high and practical skills necessary, therefore, to carry out the evaluation process is relatively concentrated, formal, rigorous, avoid the teachers "one hammer tone", which is conducive to the full range of training students ability, realize the evaluation of a dynamic process; thirdly, the basic quality of assessment to reflect the comprehensive, the ability to use comprehensive survey of students knowledge and solve problems.

\subsection{For post education demand, the use of live evaluation methods.}

The post education curriculum evaluation is not the same, therefore, in the examination according to the requirements, the use of live a variety of evaluation methods, to the maximum extent to meet the aim of teaching, to realize the goal of training.

\subsection{Adhere to the evaluation mechanism and reasonable, perfect evaluation system.}

Professional education is short time, characteristics of the periodic conversion speed training, curriculum assessment only as "a piece of paper" is difficult to fully evaluate student ability quality. Therefore, the need to establish a reasonable evaluation mechanism, comprehensive ability is also indispensable important conditions to strengthen professional education and quality of the students. In turn, the curriculum evaluation mode, also will appear in the problem back, to consummate the evaluation system.

\section{Conclusion}

In short, the examination reform education office is a very complicated system, work, promote the reform of assessment method, improving the evaluation system is an important guarantee for the deepening of educational reform and development, therefore, we need to continue research on post education evaluation concept, evaluation contents and methods and organizational forms, to explore the characteristics and rules of curriculum evaluation, promote the sustainable education reform for course assessment.

\section{References}

[1] Zhigang Gu. The sergeant education colleges around the actual deeping education reform exploration, Journal of Armored Force Technique Institute. 122 (2015) 5-8.

[2] Yali Tian, Xiaohong Liu. System design of on-post education teaching quantization appraisement, Ordnance Maintenance. 289 (2016) 16-21.

[3] Jinshan Wang, Hanfang Li. Higher education system of research and practice, Vocational Education Technology. 245 (2015) 35-39. 